\title{
A Case of Unilateral Vocal Fold Paralysis Caused by Ortner's Syndrome
}

\author{
Sang Hoo Park (D), Heon Soo Park (D), Woo Yong Bae (D), and Dong Kun Lee (iD) \\ Department of Otorhinolaryngology-Head and Neck Surgery, College of Medicine, Dong-A University, Busan, Korea
}

Ortner's 증후군에 의해 발생한 일측성 성대마비 1예

박상후, 박헌수, 배우용, 이동근

동아대학교 의과대학 이비인후-두경부외과학교실

The causes of vocal cord paralysis include iatrogenic injury during thyroid or cervical surgery, heart and chest surgery, and tumorous lesion such as laryngeal cancer and lung cancer. In addition to these common causes, rarely, cardiovascular disease can also cause vocal fold paralysis. A disease known as Cardiovocal syndrome, or Ortner's syndrome, causes left vocal fold paralysis when the left recurrent laryngeal nerve is compressed by the pulmonary artery and aorta, which is occurred by pulmonary hypertension from heart disease. We report for the first case in Korea the diagnosis of vocal fold paralysis caused by Ortner's syndrome.

Keywords Vocal fold palsy; Cardiovascular disease; Recurrent laryngeal nerve; Ortner's syndrome.

\section{서 론}

성대마비의 가장 흔한 원인으로는 의인성 손상과 종양성 질환이 있다. 의인성 성대 마비는 갑상선절제술, 심흥부 수술, 경부청소술 등의 수술 중 발생하는 되돌이후두신경 또는 미주신경의 손상으로 발생할 수 있다. 종양성 성대마비는 종양에 의한 되돌이후두 신경 또는 미주신경의 침범에 의해 발생한다. 종양 중에서는 후두암에 의한 신경 침범이 가장 흔한 원인으로 알려져 있으며 그 다음으로 폐암이 흔하다.) 이러한 일반적인 원인 이외에 심혈관계 질환이 드물게 원인이 되기도 한다. Cardiovocal 증후군, 또는 Ortner's 증후군으로 알려진 질환은 심장질환에 의해 확장된 심혈관이 좌측 되돌이후두신경을 물리적으로 압박하여 발생하는 일측성 성대마비이며 1897년 Nobert Ortner가 처음으 로 보고하였다. ${ }^{2)}$ 되돌이후두신경마비의 약 0.6 5\%가 이 증후군에 의해 발생한다고 보 고되었다. ${ }^{3}$ 국내에서는 Ortner's 증후군에 의한 성대마비 환자 사례가 보고된 바가 아직 없기에 본 저자들은 목소리 변화를 주소로 내원한 31세 여성 환자의 증례를 보고하는 바이다.
Received November 21, 2019

Revised November 26, 2019

Accepted November 28, 2019

\section{Corresponding Author}

Dong Kun Lee, MD, PhD

Department of Otorhinolaryngology-

Head and Neck Surgery,

College of Medicine, Dong-A University,

26 Daesingongwon-ro, Seo-gu,

Busan 49201, Korea

Tel $+82-51-240-5423$

Fax+82-51-253-0712

E-mail chaos001@hanmail.net

\section{ORCID iDs}

Sang Hoo Park (D)

https://orcid.org/0000-0002-5994-2428

Heon Soo Park (1)

https://orcid.org/0000-0002-4567-7272

Woo Yong Bae (D)

https://orcid.org/0000-0001-5578-0225

Dong Kun Lee (iD)

https://orcid.org/0000-0002-7296-1420

This is an Open Access article distributed under the terms of the Creative Commons Attribution Non-Commercial License (https://creativecommons.org/ licenses/by-nc/4.0) which permits unrestricted non-commercial use, distribution, and reproduction in any medium, provided the original work is properly cited. 


\section{증 례}

31세 여자 환자가 내원 2주 전 처음 발생한 목소리 변화를 주소로 본원으로 내원하였다. 과거력으로 천식이 있어 아침, 저녁으로 흡입기를 사용하고 있었으며 그 외 다른 과거 병력 및 수술 병력은 없었다. 환자는 목 통증, 목 불편감 등의 증상 은 없었으나 물을 마시면 간헐적으로 흡인 증상이 발생하였 고 평소 가벼운 운동 시 간헐적 호흡곤란이 있었다. 외래에서 시행한 후두내시경 검사에서 좌측 성대 움직임의 저하, 성대 의 휜 모습과 위축성 변화가 관찰되어 신경 지배의 손상으로 인한 좌측 성대의 마비를 시사하는 소견을 확인할 수 있었다 (Fig. 1).

환자에게 일측성 성대마비를 유발할 만한 과거력 및 수술 병력이 없었기에 성대마비의 원인을 감별하기 위해서 흥부 단순촬영과 경부 및 흥부 컴퓨터단층촬영 그리고 뇌 자기공
명영상을 촬영하였다. 뇌·신경학적 원인을 감별하기 위해 촬 영한 뇌 자기공명영상에서 뇌졸증, 뇌종양 등의 특이 소견은 나타나지 않았다. 경부 컴퓨터단층촬영에서는 갑상선이나 후두 등 되돌이후두신경의 주행에 관계된 구조물에 종물이나 염 증, 외상 등의 특이 소견은 관찰되지 않았다. 흥부 단순촬영에 서는 좌측 폐문 쪽으로 튀어나온 윤곽이 확인되었다(Fig. 2A). 흥부 컴퓨터단층촬영 영상에서 폐동맥의 지름이 약 $3.5 \mathrm{~cm}$ 가량 확장된 것이 관찰되었으며(Fig. 2B) 심장의 타원 오목 (fossa ovalis)에서 심방 사이 중격의 결손이 의심되는 병변이 확인되었다(Fig. 2C). 이러한 소견들을 바탕으로 영상학적으 로 심방중격결손 및 폐동맥 고혈압을 의심하였으며 정확한 진단 및 치료를 위해서 환자에게 흥부외과 진료 및 심장초음 파 검사를 권유하였다. 흥부외과 외래에서 시행한 심초음파 검사에서 이차공 심방중격결손, 폐동맥 고혈압이 확인되었다. 흥부외과에서는 수술을 권유하였고 환자는 아직 수술을 원
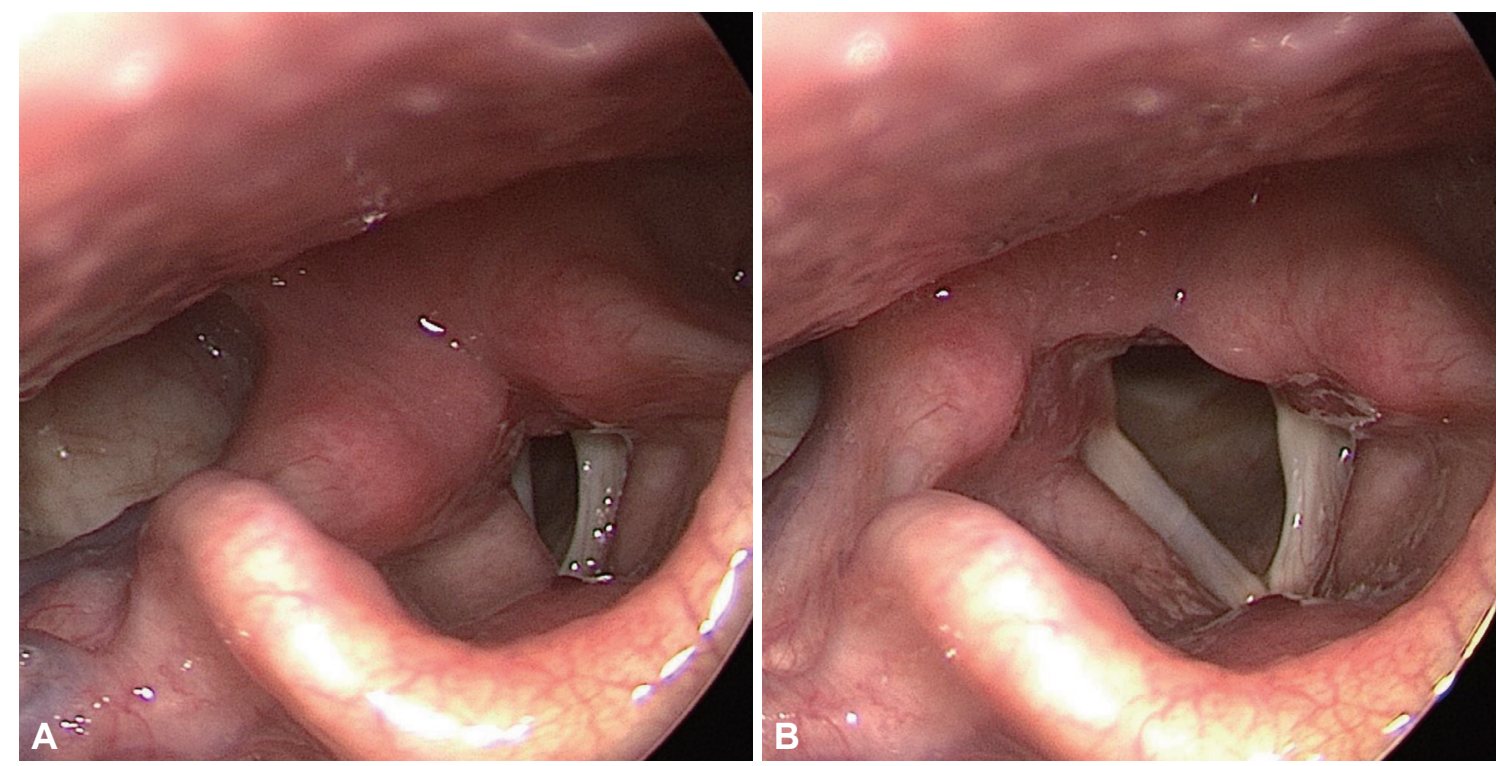

Fig. 1. Laryngoscopic exam of vocal fold. Shows left vocal fold paralysis in inspiration (A). Shows left vocal fold paralysis in expiration (B).
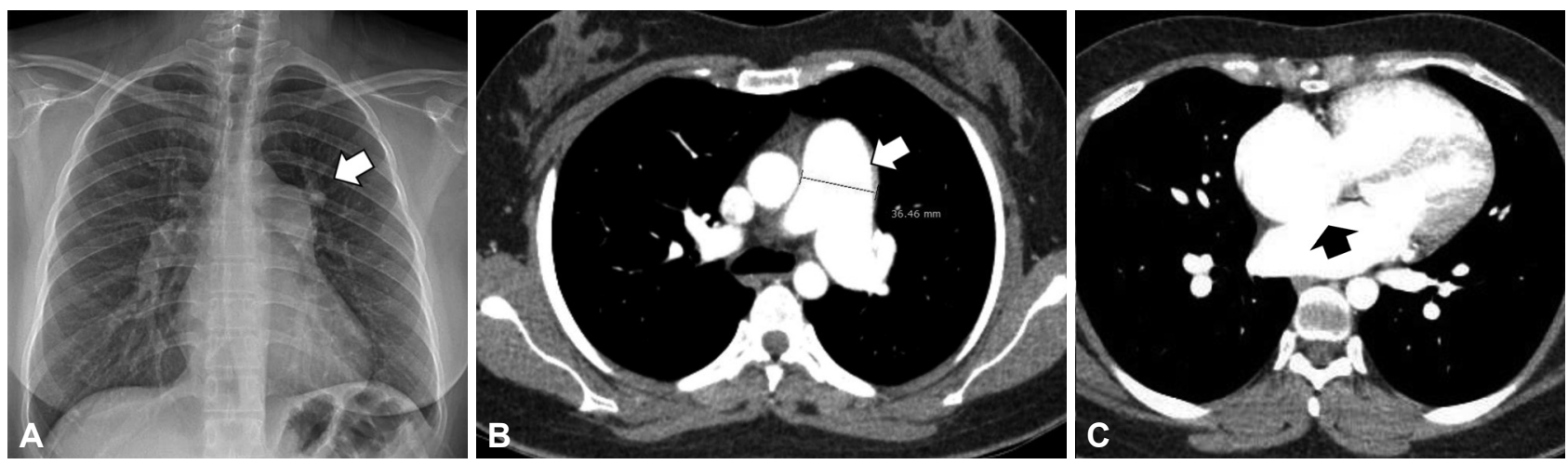

Fig. 2. Chest radiologic exam. Shows simple chest radiography showing bulging contour at the left hilar area (arrow) (A). Shows axial enhanced image of chest computed tomography showing diffuse dilatation of main pulmonary trunk (arrow) (B). Shows axial enhanced image of chest computed tomography showing suspicious interatrial septal defect in fossa ovalis (arrow) (C). 
하지 않아 2개월마다 주기적으로 외래에서 경과 관찰 중이며, 처음 외래를 방문 했을 때보다 환자의 주관적 목소리는 약간 호전 양상이었으나 후두내시경 소견은 차이가 없었다.

\section{고 찰}

되돌이후두신경은 윤상갑상근을 제외한 모든 후두내재근 들을 신경지배하여 발성과 호흡의 기능을 조절한다. 좌측, 우 측 되돌이후두신경은 동측의 좌, 우측 미주신경으로부터 갈 라져 나온다. 우측 되돌이후두신경은 우측 쇄골하동맥의 높 이에서 갈라지며 이 동맥을 감아 돌아 기관식도구를 따라 위 로 주행하여 후두로 들어간다. 좌측 되돌이후두신경은 우측 되돌이후두신경보다 길이가 더 길며 동맥관인대(ligamentum arteriosum) 뒤에 위치한 대동맥궁을 감아 돌아서 기관식도 구를 따라 위로 주행한다. 이러한 길이나 위치에 따른 주행의 해부학적 차이로 인해 좌측 되돌이후두신경이 우측보다 더 쉽게 손상을 받을 수 있다. 흥부 질환에 의해 발생하는 일측 성 대마비 중에서 좌측 성대마비가 우측 성대마비보다 약 1.75 배 더 많이 발생한다. ${ }^{4)}$

Ortner's 증후군은 1897년 Ortner ${ }^{2}$ 에 의해 처음 보고되었 다. 그는 확장된 좌측 심방에 의해서 좌측 되돌이후두신경이 압박되면 좌측 성대마비가 발생하여 환자의 목소리 변화를 유발한다고 설명했다. 이후 추가적인 연구들을 통해서 승모판 협착, 승모판 폐쇄 부전, 심방중격 결손, 심실중격 결손, 동맥 관개존증 등의 다양한 심장질환에 의해서 유발된 좌심방 확 장 혹은 폐동맥성 고혈압이 이런 증상의 원인이 될 수 있음이 확인되었고 이런 이유로 Ortner's 증후군은 Cardiovocal 증후 군으로도 불려진다. 심장질환에 의해 발생한 폐동맥성 고혈압 에 의해 확장된 폐동맥과 대동맥에 의해 좌측 되돌이후두신 경이 압박을 받게 되면 좌측 성대마비가 발생하게 되어 환자 에게 목소리 변화가 발생하는 과정이 Cardiovocal syndrome 의 기전으로 알려져 있다. ${ }^{5}$ 주로 고령의 환자에서 높은 유병율 을 보이지만 모든 연령대에서 발생이 가능하며 소아에서도 보 고된 경우가 있다. ${ }^{6}$

진단을 위한 검사로서 단순 흥부 촬영은 간편하고 흥부에 대한 기본적인 정보를 줄 수 있기 때문에 첫 영상 검사로 주로 사용될 수 있다. 추가적으로 흉부 컴퓨터단층촬영을 통해서 단순 흥부 사진에서는 확인할 수 없는 대동맥과 폐동맥의 병 변을 확인할 수 있다. 이와 같은 심혈관의 비정상적 소견이 발 견 되면 추가적인 심장초음파 검사를 통해서 심방의 비대 유 무, 폐동맥 확장 등의 심장 구조 이상을 확인한다. 치료에 있 어서 빠른 진단이 가장 중요한 요소인데 이는 신경의 회복가 능성이 압박을 받은 시기에 비례하기 때문이다.7) 그렇기 때문
에 병을 않게 된 기간이 예후의 가장 중요한 요소이다. 가장 주된 치료법은 환자의 근원적인 심장질환을 치료하는 것이다. 실제로 수술 및 시술을 통해서 심장질환을 치료한 이후 목소 리 변화가 호전되는 경우가 몇 차례 보고된 바 있다. ${ }^{8)}$ 승모판 협착증에 의해 Cardiovocal 증후군이 발생한 45세 남자 환자 가 승모판 대치술을 받은 이후 쉰 목소리의 호전을 보인 사례 가 보고된 바 있다.9) 하지만 환자가 만약 수술을 할 수 없는 상황이면서 증상이 점점 악화되면 일반적인 일측성 성대마 비의 치료 방법에 따라 음성 치료 또는 성대 주입술 등을 생 각해 볼 수 있다.9) 일측성 성대마비가 특히 좌측에 발생하는 경우는 Ortner's 증후군과 같은 드물지만 심혈관계 원인을 고 려해야 하며, 흥부 단순 촬영이나 컴퓨터단층촬영 등을 통해 조기에 진단하여 치료할 수 있는 노력이 필요하다.

중심 단어: 성대 마비, 심혈관 질환, 되돌이후두신경, 오트너 증후군.

Acknowledgments

None.

Conflicts of Interest

The authors have no financial conflicts of interest.

Authors' Contribution

Conceptualization: Woo Yong Bae. Formal analysis: Dong Kun Lee. Investigation: Sang Hoo Park. Methodology: Dong Kun Lee. Project administration: Heon Soo Park. Resources: Dong Kun Lee. Supervision: Dong Kun Lee, Woo Yong Bae. Validation: Dong Kun Lee. Visualization: Sang Hoo Park. Writing_original draft: Sang Hoo Park. Writing - review \& editing: Dong Kun Lee. Approval of final manuscript: all authors.

\section{REFERENCES}

1. Benninger MS, Gillen JB, Altman JS. Changing etiology of vocal fold immobility. Laryngoscope 1998;108(9):1346-50.

2. Ortner N. Recurrent laryngeal nerve paralysis due to mitral valve stenosis. Wien Klin Wochenschr 1897;10:753-5.

3. Solanki SV, Yajnik VH. Ortner's syndrome. Indian Heart J 1972;24(1): 43-6.

4. Song SW, Jun BC, Cho KJ, Lee S, Kim YJ, Park SH. CT evaluation of vocal cord paralysis due to thoracic diseases: a 10-year retrospective study. Yonsei Med J 2011;52(5):831-7.

5. Paquette CM, Manos DC, Psooy BJ. Unilateral vocal cord paralysis: a review of CT findings, mediastinal causes, and the course of the recurrent laryngeal nerves. Radiographics 2012;32(3):721-40.

6. Zaki SA, Asif S, Shanbag P. Ortner syndrome in infants. Indian Pediatr 2010;47(4):351-3.

7. Heikkinen J, Milger K, Alejandre-Lafont E, Woitzik C, Litzlbauer D, Vogt JF, et al. Cardiovocal syndrome (ortner's syndrome) associated with chronic thromboembolic pulmonary hypertension and giant pulmonary artery aneurysm: case report and review of the literature. Case Rep Med 2012;2012:230736.

8. Monwarul Islam AK, Zaman S, Doza F. Ortner syndrome due to concomitant mitral stenosis and bronchiectasis. Korean Circ J 2012;42(7): 507-10.

9. Tammiraju I, Radha Krishna T, Vittal Prasad P, Jagadish Babu K. Ortner's syndrome (cardio vocal hoarseness)-a rare entity in modern era. a case report. IHJ Cardiovascular Case Reports (CVCR) 2018;2(2):82-4. 